\title{
Catheter Care Bundle and Low Catheter Related Bloodstream Infection Rates in a Home Parenteral Nutrition Population; a 4 Year Observational Study
}

Mark DeLegge ( $\sim$ drmark@deleggemedical.com )

Coram CVS Specialty Infusion Services https://orcid.org/0000-0003-3960-9326

Karen Sexton Hamilton

Coram CVS Specialty Infusion Services

Melissa Leone

Coram CVS Specialty Infusion Services

\section{Allyson Checkley}

Coram CVS Specialty Infusion Services

Research article

Keywords: Bloodstream infections, central venus catheters, home parenteral nutrition

Posted Date: November 23rd, 2020

DOI: https://doi.org/10.21203/rs.3.rs-42494/v2

License: (1) This work is licensed under a Creative Commons Attribution 4.0 International License.

Read Full License 


\section{Abstract}

Home Parenteral Nutrition (HPN) is often a life-saving therapy for patients. One of the most common complications for HPN is catheter-related blood stream infections (CRBSI). In the home setting there is no single defined "care bundle" for the on-going maintenance of central venous catheters (CVC) for the prevention of CRBSI. We evaluated the impact of a standardized catheter care bundle in patients receiving HPN on the incidence of CRBSI. Methods: Data collection included use of standardized tools and processes to capture patient demographics, catheter complications including CRBSI and some associated risk factors. Reported data was collected and analyzed annually and compared year-to-year from the years 2014-2017 from one national home infusion company. CRBSI reported as number of infections/1000 catheter days

Results: The CRBSI rate/1000 days was reported as 0.43, 0.31, 0.30 and $0.23(2014,2015,2016,2017$ respectively) statistically significant difference $(p<.05)$ between the years 2014 and 2017. CRBSI.

Conclusion: The use of a catheter care bundle in an HPN population may have contributed to a 4-year reported outcomes of low and continuously declining CRBSI in a large, diverse United States-based HPN population.

\section{Clinical Relevancy Statement}

Catheter-related blood stream infections are a common complication of HPN therapy. There is no consensus on the clinical approach to prevention of CRBSI in the home setting. This study evaluated a catheter care bundle approach for the prevention of CRBSI in a large number of HPN patients.

\section{Background}

Home parenteral nutrition (HPN) is a treatment for patients with an inability to receive nutrients into and/or absorb nutrients from the small intestine. In general, patients receiving HPN are stable from a medical perspective and do not require hospitalization or care in a supervised medical facility.

Patients require a central venous catheter (CVC) for infusing PN (parenteral nutrition) solutions and sometimes other medical therapy. Because of the presence of a CVC, HPN patients are at risk for the development of catheter-related bloodstream infections (CRBSI). Of the reported complications of HPN therapy related to the CVC, CRBSI is the most common and is associated with significant morbidity and sometimes, mortality. (1)

In addition to PN preparation and infusion, a patient and/or caregiver often must provide ongoing care for the CVC. Sometimes, a homecare nurse provides this care during weekly visits. Maintenance care includes activities such as catheter dressing, injection cap changes and flushing of the CVC lumen(s). 
The majority of CRBSI stem from the flora found on the patient's skin. It is of utmost importance that the skin around the catheter insertion site be properly cleansed.(2) Overwhelming evidence has shown that using a $2 \%$ chlorhexidine antiseptic cleansing solution reduces the rate of CRBSI by up to $50 \%$.(3) There are published reports on the importance of additional interventions to prevent CVC infection in the home setting including the use of disinfecting catheter injection caps, PICC stabilization devices, specialized dressings to prevent microbial growth, and dressing protection from water during bathing. (4-6) Patient and caregiver education are also important. Very few consensus professional society guidelines for care and maintenance of CVC in the HPN population exist.(7)

Assessments have been made to understand the risk factors that a patient, caregiver or home setting may possess that would increase a patient's likelihood of developing CRBSI.(8-10) This can include, but is not limited to, shorter lengths of small bowel remaining after small bowel resection, patient history of alcohol, opioid or anti-anxiolytic drug dependence, lower socioeconomic status and a higher number of family dependents living in the home. Not all home settings are similar with regards to cleanliness and organization. There also is variation in a patient or caregiver's ability to follow instructions.(11)

Vast improvements have been made in the reduction of CRBSI in the hospital setting attributed to standardization of the CVC insertion procedure. The groundbreaking Keystone Project demonstrated the effect of five measures (a bundle) on the improvement of outcomes during insertion of central venous catheters.(12) Those components included hand washing prior to CVC placement, chlorhexidine skin preparation, full barrier precautions, use of the subclavian vein as the preferred access site and early removal of all unnecessary CVC. However, even in institutions where full compliance with the bundle exists, CRBSI are still occurring.(13) Of note, the Keystone Project central line bundle does not include any of the post-insertion aspects of CVC care and management which have been shown to prevent CVC infection.(14)

The current study was initiated by a specialty pharmacy in the United States providing patient-specific compounded HPN in addition to a variety of specialized medications to a diverse patient population with multiple physician providers. The decision to pursue this study was based on the findings that HPN CRBSI rates were reported in the literature as persistently higher than other home infusion therapies, thus indicating a higher risk level for these patients.(15) Prior to 2014, internal data revealed a persistence of CRBSI in the HPN population of a large, national specialty pharmaceutical provider. It was hypothesized that a dedicated catheter care and maintenance bundle, using best available evidence, would reduce the overall number of CRBSI in an HPN population. A multi-modality catheter care bundle (CCB) including patient education and the use of novel catheter maintenance products was chosen to ensure mitigation of the risks associated with several known contributors to CRBSI, including skin contamination, catheter injection cap antisepsis, catheter pistoning and compromised or wet IV dressings.

\section{Methods}


A retrospective, non-randomized analysis was completed on an average of 7385 patients/year receiving HPN from a single national specialty pharmaceutical provider from January 1, 2014 to December 31, 2017. The primary outcome measure was development of CRBSIs which is expressed as the number of CRBSIs per 1,000 catheter days of HPN use by patients in that year. PN use by patients in a given year. This data was compared year over year from 2014 through 2017. Data collected included demographic information, catheter type, number of catheter lumens and organisms responsible for the catheter infections when cultured.

As part of nutrition assessment, the Registered Dietitians completed a catheter history at the start of care, assessed compliance to catheter care as part of the ongoing nutrition assessment, and provided on-going education. The education provided reinforced catheter management techniques. On-going patient interactions with a nurse in the home, clinical support specialist or pharmacist provided additional opportunities for catheter assessment and/or potential to capture a catheter event. All confirmed catheter events were then documented in the pharmacy provider's computer system.

Data was pulled from the pharmacy provider's computer system using a specialized query tool. No individualized chart review was performed. Two or more reported catheter infections occurring in the same patient in a 12-month period were reported to a Clinical Manager or designee to determine alternative care strategies and recommended follow-up education on an as-needed basis based on catheter complication rates, unused supplies and demonstrated non-compliance.

All HPN patients who were not ordered an institution or clinician-specific catheter care protocol were provided with the CCB that consisted of 4 commercially available medical products which included:

1) $70 \%$ alcohol impregnated disinfection end cap

2) Foam disc impregnated with polyhexamethylene biguanide hydrochloride

3) Moisture barrier to help protect the intravenous dressing during showering.

4) Securement device for PICC.

All patients received standard CVC catheter maintenance care which included regular catheter flushing, regular timing for injection cap change out, appropriate use of catheter securement devices, appropriate use of extension sets, routine catheter dressing changes and safe catheter clamping techniques.

In conjunction with the $\mathrm{CCB}$, an education program was initiated consisting of:

1. An internal education on the CCB to all home infusion nurses, pharmacists, dietitians and supporting nonclinical staff,

2. A letter outlining the $\mathrm{CCB}$ and its associated education program sent to the patients and their physicians 
3. Specific patient education tools that addressed both catheter supply use and general guidelines for effective catheter care.

This education was provided in addition to the direct education provided to patients and caregiver(s) on how to effectively use the CCB. Patients were also provided with a laminated mat that was to be used as the location to prepare their prescribed PN. This mat contained instructions for maintaining aseptic technique and provided reminders about CVC maintenance strategies for avoiding CVC complications, including CRBSI. The mat could also be easily cleaned prior to use. Catheter locking of solutions for prevention of CRBSI was not a common practice and was not part of the intervention program.

Catheters were categorized as central catheters non-tunneled (CCNT), central catheters tunneled (CCT), peripherally-inserted catheters (PICC) and PORT. A catheter-related bloodstream infection was defined as when a patient exhibits the following symptoms: fever over 100.6F (38.1C) not attributable to other health issues; catheter exit-site redness, drainage or cord; and also has either blood/catheter culture or Gram stain confirmation of bacterial or fungal counts, or the prescriber determines that the catheter is the most likely source of infection, thus removing the catheter or treating the patient/catheter with anti-infectives. If the CRBSI symptoms develop less than 48 hours following hospital discharge, this would be considered a nosocomial infection, and not applicable to the home infusion setting. CRBSI symptoms developing 48 hours or more after central line insertion and care in the home infusion setting would be considered a nosohusial infection.(16) Patients admitted to the hospital for catheter infections were captured as part of the documentation process.

This was an observational study without patient randomization. Descriptive statistical reporting was performed on all collected data. Comparisons were made between independent variables using the Chi square $(x)^{2}$. A $p<.05$ was considered statistically significant

All patient data was deidentified. CORAM/CVS internal clinical/ethics research committee reviewed the study and determined that it meets the criteria of 45 CFR 46101(b). Our research involved the "collection of existing data, documents, records" and "information is recorded by the investigator in such a manner that the subjects cannot be identified directly or through identifiers linked to the subjects".

\section{Results}

There was patient PN exposure data available for the years between 2016-2018. On average for these three years, $68 \%$ of the HPN patients were on PN > 90 days with an average of 657 days (range 647-670 days). Thirty-two percent of the patients were on $\mathrm{PN}<90$ days with an average of 43 days (range $42-45$ days).

For the four years of data evaluated, patient demographics remained stable with the mean patient age of 46 years $(1.17 \mathrm{SD})$, with $18 \%<16$ years of age; $82 \% 17$ years of age or older. Of the prescribers who managed this patient population, $86 \%$ manage $1-2$ TPN patients per year and $14 \%$ managed $>2$ TPN patients/year. 
A total of 6933, 7576, 7389 and 7642 patients were followed in 2014, 2015, 2016 and 2017 respectively. The top 5 ICD 10 codes for diagnosis were malnutrition (23\%), post-surgical malabsorption (15\%), malabsorption (6\%), reginal enteritis (5\%) and small bowel obstruction (4\%). Eighteen percent of the population was pediatric with the 2 largest representative populations of 30-49 (21\%) and 50-64 (31\%). The CRBSI rates for patients receiving HPN from 2014 to 2017 is shown in Table 1. There was a downward trend in CRBSI/1000 catheter days from 2014 to 2017. The reduction in the number of CRBSI/ 1000 catheter days between years 2014 and 2017 was statistically significant $(p<.05)$

Table 2 notes the specific number and the type of central venous catheters utilized/year and the dwell time of these catheters in days. Central tunneled catheters represented the largest overall number of CVC and had the longest overall dwell time in days. Central nontunneled catheters represented the least number of CVC in the study with the least number of overall dwell days. Triple lumen catheters (TLC) had the lowest CRBSI/1000 days numerically. (Table 3) However, TLC accounted for $5 \%$ or less of the total catheters used on a year to year basis. Because of this very low number, TLC were not included in any further statistical comparison. In the year 2014, single lumen catheters (SLC) had significantly fewer CRBSI as compared to double lumen catheter (DLC) $(p<.05)$. In the years 2015 and 2106 single lumen catheters had numerically fewer CRBSI as opposed to double lumen catheters although these values did not reach statistical significance.

On average for the four years studied, seventy-nine percent of reported CRBSI had an associated documented organism(s) (2014-76\%, 2015-76\%, 2016-86\% 2017 -78\%). For those CRBSI where blood culture results were available, we divided the organisms into 3 distinct groups based on the categorization of fungal (i.e. Candida), skin-based bacterial organisms (ie. Staphylococcus) or gastrointestinal/respiratory-based bacterial organisms (i.e. Enteroccous) (Figure 1). This distinction was made because of our desire to understand the initial location of the catheter-infecting organisms (fungal, skin-based or gastrointestinal/respiratory secretions). Table 4 provides an example of the taxonomy crosstalk that was used to create the 3 reported groups. Based on this categorization, fungal organisms were the least likely cause of CRBSI when evaluated by percentage of the total available documented organisms. Fungal infections were responsible for significantly less percentage of overall infections $(p<.05)$ CRBSI as compared to skin-based bacterial organisms for the years 2014, 2016 and $2017(p<.05)$. For the year $2014(p<.05)$, fungal infections were responsible for significantly lower percentage of CRBSI as compared to gastroenterology/respiratory-based bacterial organisms. There were no significant differences in percentages of CRBSI between skin- and gastroenterology/respiratory-based bacterial organisms for any of the reported years.

\section{Discussion}

This 4-year observational experience with a bundled catheter care program demonstrated a low and declining CRBSI rate as reported per one thousand catheter days. The population of HPN patients was diverse with a multitude of clinicians providing the care for the HPN patient. Most of these physicians 
managed 1-2 HPN patients per year. The bundled, standardized approach to catheter care may have contributed to this low incidence of CRBSI.

The incidence of CRBSI remains a topic of reporting from many clinicians and institutions. Table 5 provides a listing of reference articles for CRBSI infection in the HPN population and the reported CRBSI rates.(17 - 29) Only studies that included greater than 100 patients that were published since the year 2000 are listed in this table. These studies report a CRBSI rate between $0.35-3.20$ per 1000 catheter days. These reports were also observational in nature. Some of the reports were based on surveys. No attempt was made to implement a specific CRBSI practice in these publications other than the practice that was ordered by the responsible clinician or was the standard of practice for the pharmacy compounding the PN or the nursing agency providing care for the HPN patient. The definition of CRBSI varied between the reported studies. There was no bundled approach to catheter care and maintenance. Many of these reports were single center reports and therefore do not represent a diverse patient population where multiple physicians are caring for patients at multiple unique sites. The majority of these studies reported out on only a small fraction of the number of patients included in this study. Specifically evaluating the 3 papers published during the time period of this study $(21,28,29)$ other than standard patient teaching, only the Vashi publication used one of the products mentioned in the catheter care bundle described in this paper. Interestingly, the Vashi paper also had the lowest reported catheter infection rate/ 1000 catheter days of these 3 publications.

The use of antimicrobial dressings has been shown to have an impact on CVC infections. The antimicrobial dressing in our bundle contains $0.2 \%$ polyhexamethylene biguanide (PHMB). $\mathrm{PHMB}$ is an antibacterial polymer and has been shown to inhibit bacterial growth. $(\mathbf{3 0 , 3 1 )}$

Protective moisture barriers are placed over the CVC site and catheter during times of exposure to water, such as taking a shower. They replace hand-made devices such as a plastic bag placed over the CVC. The use of a protective cover from exposure to tap water contamination during showering and bathing has been shown to have an impact on CVC infections. $(32,33)$

Disinfecting caps are used for needle-free intravascular connections. The cap itself contains $70 \%$ isopropyl alcohol on a sponge. A trauma intensive care unit (ICU) study demonstrated that the addition of a disinfecting cap to existing standard central line care bundles resulted in a $40 \%$ decrease in CRBSI.(34) Another study with a disinfecting cap was performed on adult patients with peripherally inserted central venous catheters (PICC) Compared to the baseline practice of catheter hub scrubbing alone, the use of a disinfecting cap reduced CRBSI.(35)

Peripherally inserted central venous catheters can cause vein damage, access site tissue inflammation and CRBSI if the PICC is not secured properly. A poorly secured PICC can "piston" in and out of a vascular access site, resulting in the delivery of skin-based microorganisms into the vein. Vascular access stabilization devices have been shown to reduce complications compared to unsecured CVCs, including CRBSI.(36) 
Patient education is an important component of the care and management of CVC to prevent complications. The European Society of Parenteral and Enteral Nutrition Guidelines state that education should be provided to HPN patients. The teaching program should include catheter care, pump use, and preventing, recognizing and managing complications. (37) No time limits for training should be set; patients should be allowed to make progress at their individual pace.(38) It has been reported that patients who receive more detailed written and oral information on the aseptic management of catheters have a lower incidence of catheter sepsis.(39) It has also been reported in pediatric HPN patients that one of the factors improving the longevity of a CVC, including a reduction in associated infectious complications, was improved teaching of patients.(4) The current study did include educational activites as part of the bundled approach to catheter care.

This study has its limitations. It is a retrospective, observational study. No attempt was made to equalize patient groups with regards to demographics or disease co-morbidities which may have impacted patient outcomes, including catheter related-bloodstream infections. Patient compliance with the CCB was not tracked. We did not collect data on a patient's gastrointestinal anatomy, socioeconomic status, level of education or degree of family support which experts have opined are risk factors for the development of CRBSI. In addition, we did not review each patient's complete medical record as there are limitations in the completeness of the medical record in the home care setting as opposed to the hospital setting. However, the number of patients reported in this study is the largest report of any HPN database; these large patient numbers can often mitigate result errors noted in retrospective clinical study designs. We do acknowledge that studies with large patients also can result in statistically significant findings that are not ultimately clinically significant.

\section{Conclusion}

Home parenteral nutrition is a lifesaving therapy. Catheter-related bloodstream infection remains a common complication of the HPN population. In this study, we successfully achieved a reduction in CRBSI with the use of a bundled CVC care pathway designed to standardize safe maintenance practice after CVC insertion.

\section{Abbreviations}

CCB - catheter care bundle

CCT - central catheter tunneled

CCNT - central catheter non-tunneled

CRBSI - catheter-related blood stream infections

CVC - central venous catheter 
DLC - double-lumen catheter

HPN - home parenteral nutrition

PICC - peripherally inserted central venous catheter

PHMB - polyhexamethylene biguanide

$\mathrm{PN}$ - parenteral nutrition

SLC - single lumen catheter

TLC - triple lumen catheter

\section{Declarations}

Ethics Approval and Consent to Participate: This was a retrospective analysis of data in humans. All patient data was deidentified. CORAM/CVS internal clinical/ethics research committee reviewed the study (the Clinical Program Review Committee), and determined that it meets the criteria of 45 CFR 46101(b). Our research involved the "collection of existing data, documents, records" and "information is recorded by the investigator in such a manner that the subjects cannot be identified directly or through identifiers linked to the subjects". No consent was required from the de-identified subjects

Consent to Publish: All Authors and CoramCVS have given consent to publish the article

Availability of Data and Materials: Available from $\mathrm{KH}$ upon reasonable request

Competing Interests. $\mathrm{KH}, \mathrm{ML}, \mathrm{AC}$ are employees of Coram/CVS. MD is a consultant for Coram/CVS

Funding: No funding was received for this manuscript

Author's Contribution; $\mathrm{KH}$ and MD designed and contributed to the writing of the manuscript. $\mathrm{ML}$ and $\mathrm{KH}$ analyzed the data and contributed to the writing of the manuscript. AC and MD edited numerous versions of the manuscript and contributed to the writing of the manuscript. All authors read and approved the final manuscript

Acknowledgements; None

\section{References}

1. Wanten G, Calder P, Forbes A. Managing adult patients who need home parenteral nutrition. Br Med J 2011;342:696-701.

2. Olson C, Heilman JM. Clinical performance of a new transparent chlorhexidine gluconate central venous catheter dressing. J Assoc Vasc Access 2008;13: 13-19. 
3. Chambers ST, Sanders S, Patton WN, Ganly P, Birch M., Crump JA, Spearing Reduction of exit-site infections of tunneled intravascular catheters among neutropenic patients by sustained-release chlorhexidine dressings: results from a prospective randomized controlled trial. J Hosp Infect 2005;6:53-61.

4. Moukarzel AA, Haddad I, Ament ME, Buchman AL, Reyen L, Maggioni A, et al. 230 patient years of experience with home long-term parenteral nutrition in childhood: natural history and life of central venous catheters. J Pediatr Surg.1994;29:1323-1327.

5. Stone PW, Larsen E, Kawar LN. A Systemic Audit of Economic Evidence Linking Nosocomial Infections and Infection Control Interventions: 1990 - 2000. American Journal of Infection Control 2002: 30: 145 - 152.

6. Do AN, Ray BJ, Banerjee SN, Illian AF, Barnett BJ, Pham MA, et al. Bloodstream infections associated with needleless device use and the importance of infection-control practices in the home health care setting. J Infect Dis. 1999;179:442-448.

7. Cawley C, Lai S, Nightingale J, Small M. British international failure alliance (BIFA) guidance. Standardised parenteral support catheter guidelines. April 2018. https://www.bapen.org.uk/pdfs/bifa/standardised-parenteral-support-catheter-guidelines.pdf

8. Richards DM, Scott NA, Shaffer JL, Irving M. Opiate and sedative dependence predicts a poor outcome for patients receiving home parenteral nutrition. J Parenter Enteral Nutr 1997;21:336-338.

9. Chang A, Enns R, Saqui O, Chatur N, Whittaker S, Allard JP. Line sepsis in home parenteral nutrition patients: are there socioeconomic risk factors. A Canadian Study. J Parenteral Enteral Nutr 2005;29:408-412.

10. Reimund JM, Arondel Y, Finck G, Zimmermann F, Duclos B, Baumann R. Catheter-related infections in patients on home parenteral nutrition: results of a prospective study. Clin Nutr 2002;21:33-38.

11. Gifford H, Delegge MH, Epperson LA. Education methods and techniques for training home parenteral nutrition patients. Nutr Clin Prac 2010;25:443-450.

12. Pronovost P, Needham D, Berenholtz S, Sinopoli D, Chu H, Cosgrove S, et al. An intervention to decrease catheter-related bloodstream infections in the ICU: Keystone Project. The New Engl J Med 2006;355: 2725-2732.

13. Davis J. Central-line-associated bloodstream infection: comprehensive, data-driven prevention. Pennsy/vania Patient Safety Authority 2011;8:100-104.

14. Pronvost PJ, Watson SR, Goeschel C. Sustaining reductions in central-line associated bloodstream infections in Michigan intensive care units: a 10-year analysis. Am J Qual Med 2016;31:197-202.

15. Crispin A, Thul P, Arnold D, Schild S, Weimann A. A central venous catheter complications during home parenteral nutrition: a prospective pilot study of 481 patients with more than 30,000 catheter days. Onkologie 2008;31:605-609.

16. Elfassy S, Kassam Z, Amin F, Khan KJ, Haider S, Armstrong D. Epidemiology and risk factors for bloodstream infections in a home parenteral nutrition program. J Parent Ent Nutr 2015;39:147-153. 
17. Ireton-Jones C, Delegge M. Home parenteral nutrition; a five-year retrospective evaluation of outcomes of patients receiving home parenteral nutrition support. Nutrition; 2005:21:156-160. 2005

18. Lloyd DA, Vega R, Bassett P, Forbes P, Gabe SM. Survival and dependence on home parenteral nutrition: experience over a 25-year period in a UK referral Centre. Aliment Pharm Ther 2006;24:12311240.

19. Santarpia L, Pansanisi F, Alfonsi L, Violante G, Tieso D, DeSimone G, et al. Prevention and treatment of implanted central venous catheter (CVC) -related sepsis: a report after 6 years of home parenteral nutrition. Clin Nutr 2002;21:207-21124.

20. Ugur A, Marshdeb BH, Gottsclack I, Mortensen P, Staun M, Jeppesen BP. Home parenteral nutrition in Denmark in the period from 1996 to 2001. Scand J Gastroenterol 2006;41:401-407.

21. Violante G, Alfonsi L, Santarpia L, Cillis MC, Negro G, DeCaprio C, et al. Adult home parenteral nutrition: a clinical evaluation after 3-year experience in a southern European Center. Eur $\mathrm{J}$ Clin Nutr 2006;60:58-61.

22. Cotogni P, Pittiruti M, Barbaro C, Mongo T, Palmo A, Boggio B. Catheter-related complications in cancer patients on home parenteral nutrition: a prospective study of over 51,000 catheter days. $J$ Parent Ent Nutr 2013;37:375-383.

23. Vashi PG, Vriginkar N, Popiel B, Edwin P, Gupta D. Incidence of factors associated with catheterrelated bloodstream infection in patients with solid tumors on home parenteral nutrition managed using a standardized catheter care protocol. BMC Infec Dis 2017;17:372-379.

24. Dibbs MJ, Abraham A, Chadwick PR, Schaffer JL, Teubner A, Carlson GL, et al. Central venous catheter salvage in home parenteral nutrtion catheter-related bloodstream infections: long-term safety and efficacy data. J Parent ent Nutr 2016;40:699-704

25. Cazzangia A, Serralta V, Davis S, Orr R, Eagelstein W, Metz PM. The effect of antimicrobial gauze dressing impregnated with 0.2-percent polyhexamethylene biguanide as a barrier to prevent Pseudomonas aeruginosa wound invasion. Wound 2002;14:169-176.

26. Rosin M, Welk A, Bernhardt O, Ruhnav M, Pitten FA, Kocher T, et al. Effect of a polyhexamethylene guanide mouth rinse on bacterial counts and plaque. J Clin Peridontol 2008;28:1121-1126.

27. Altman S. Showering with central venous catheters: experience using the CD 1000 composite dressing. Dialysis Transpl 2006;35:320-327.

28. O'Grady NP, Alexander M, Burns LA, Dellinger P, Garland J, Heard SO, et al. summary of recommendation guidelines for the prevention of intravascular catheter related infections. Clin Infect Dis 2011;52:1087-1099.

29. Merrill KC, Sumner S, Linford L, Taylor C, Macintosh C. Impact of a universal disinfectant cap on central line-associated bloodstream infection. Am J Infect Control 2014;42:1274-1277.

30. Wright M-O, Tropp T, Schora DM, Dillon-Grant M, Peterson K, Boehm S, et al. Continuous passive disinfection of catheter hub prevents contamination and bloodstream infection. Am J Infect Control 2013;41:33-38. 
31. Yamamoto AJ, Solomon JA, Soluen MC, Tong J, Parkinson K, Shears GJ. Sutureless securement device reduce complications of peripherally inserted central venous catheters. J Vasc Intervent Radiol 2002;13:77-81.

32. Staun M, Pironi L, Bozzetti F, Baxter J, Forbes A, Joly F. ESPEN guidelines on parenteral nutrition: home parenteral nutrition in adult patients. Clin Nutr 2009;28:467-479.

33. Wengler A, Micklewright A, He'buterne X, Bozzetti F, Pertkiewicz M, Moreno J, et al. Home parenteral nutrition teaching practice in Europe. Clin Nutr 2002:21-42.

34. Shirtoni N, Inio T, Numeta K, Kameoka S. Complications of central venous catheters in patients on home parenteral nutrition: an analysis of 68 patients over 16 years. Surg Today 2006;36:420-424.

\section{Tables}

Table 1 - Total Catheter Days Per Year and CRBSI

\begin{tabular}{|r|l|l|l|}
\hline Year & Total Catheter Days & \# CRBSI & CRBSI rate per 1000 catheter Days \\
\hline$* 2014$ & 682,590 & 294 & .43 \\
\hline 2015 & 820,232 & 256 & .31 \\
\hline 2016 & 801,271 & 243 & .30 \\
\hline$* 2017$ & 834,985 & 196 & .23 \\
\hline
\end{tabular}

$* \mathrm{P}<.05$

Table 2 - Number of catheters and catheter days by catheter type per year

\begin{tabular}{|l|l|l|l|l|}
\hline Year & $\begin{array}{l}\text { Central (non-tunneled) \# } \\
\text { catheters }\end{array}$ & $\begin{array}{l}\text { Central (tunneled) \# } \\
\text { catheters }\end{array}$ & $\begin{array}{l}\text { PICC \# } \\
\text { catheters }\end{array}$ & $\begin{array}{l}\text { Port \# } \\
\text { catheters }\end{array}$ \\
\hline $\mathbf{2 0 1 4}$ & 53 & 1400 & 4802 & 1241 \\
\hline $\mathbf{2 0 1 5}$ & 60 & 1374 & 4396 & 1168 \\
\hline $\mathbf{2 0 1 6}$ & 56 & 1031 & 4282 & 1000 \\
\hline $\mathbf{2 0 1 7}$ & 46 & 1506 & 7348 & 1534 \\
\hline & $\begin{array}{l}\text { Central (non-tunneled) } \\
\text { catheter days }\end{array}$ & $\begin{array}{l}\text { Central (tunneled) } \\
\text { catheter days }\end{array}$ & $\begin{array}{l}\text { PICC } \\
\text { catheter } \\
\text { days }\end{array}$ & $\begin{array}{l}\text { Port } \\
\text { catheter } \\
\text { days }\end{array}$ \\
\hline $\mathbf{2 0 1 4}$ & 6826 & 211603 & 348121 & 116040 \\
\hline $\mathbf{2 0 1 5}$ & 5725 & 253197 & 417064 & 144246 \\
\hline $\mathbf{2 0 1 6}$ & 7859 & 233665 & 423997 & 135751 \\
\hline $\mathbf{2 0 1 7}$ & 3959 & 194636 & 477020 & 159370 \\
\hline
\end{tabular}

Table 3 - Catheter Lumens and CRBSI 


\begin{tabular}{l|l|l|l|l|l|l|l|l|l|l|}
\hline $\mathrm{r}$ & $\begin{array}{l}\text { Total } \\
\text { Catheter } \\
\text { Days }\end{array}$ & $\begin{array}{l}\text { Single } \\
\text { Lumen }\end{array}$ & $\begin{array}{l}\# \\
\text { CRBSI }\end{array}$ & $\begin{array}{l}\text { Single Lumen } \\
\text { CRBSI/1000 } \\
\text { Days }\end{array}$ & $\begin{array}{l}\text { \% } \\
\text { Double } \\
\text { Lumen }\end{array}$ & $\begin{array}{l}\# \\
\text { CRBSI }\end{array}$ & $\begin{array}{l}\text { Double } \\
\text { Lumen } \\
\text { CRBSI/1000 } \\
\text { Days }\end{array}$ & $\begin{array}{l}\# \\
\text { CRBSI }\end{array}$ & $\begin{array}{l}\text { Triple } \\
\text { Lumen }\end{array}$ & $\begin{array}{l}\text { Triple } \\
\text { Lumen } \\
\text { CRBSI/1000 } \\
\text { days }\end{array}$ \\
\hline 14 & 682590 & 46.6 & 0 & $.00 *$ & 50.7 & 118 & $.17 *$ & 13 & 2.6 & .02 \\
\hline 15 & 820323 & 48.9 & 111 & .14 & 48.3 & 140 & .17 & 5 & 2.6 & .01 \\
\hline 16 & 801271 & 48.9 & 101 & .13 & 48.3 & 126 & .16 & 11 & 2.7 & .01 \\
\hline 17 & 836764 & 42.8 & 100 & .12 & 52.2 & 82 & .10 & 6 & 5.0 & .01 \\
\hline
\end{tabular}

$* p<.001$

TLC accounted for $5 \%$ or less of the total catheters used on a year to year basis. Because of this very low number, TLC were not included in any further statistical comparison.

\section{Table 4 Taxonomy Crosswalk: Examples}

\begin{tabular}{|l|l|l|}
\hline Skin organism & GI/Lung_organism & Fungal organism \\
\hline Staphylococcus epidermidis & Escherichia coli & Candida tropicalis \\
\hline Staphylococcus hominis & Pseudomonas aeruginosa & Candida albicans \\
\hline Xanthimonas maltophilia & Klebsiella pneumoniae & Mycobacterium \\
\hline Staphylococcus aureus & Enterococcus faecalis & Candida glabrata \\
\hline Gram positive cocci & & \\
\hline
\end{tabular}

Table 5 - CRBSI in HPN Patients in Published Reports of Greater than 100 Patients Since the Year 2000

\begin{tabular}{|l|l|l|l|}
\hline Author & Patient Number & CRBSI Rate & Year \\
\hline Bozzetti et al (18) & 447 & $.93 / 1000$ catheter days & 2002 \\
\hline Colomb et al (19) & 302 & $1.20 / 1000$ catheter days & 2007 \\
\hline Crispin et al (20) & 481 & $0.54 / 1000$ catheter days & 2008 \\
\hline Elfassy et al (21) & 155 & $2.0 / 1000$ catheter days & 2015 \\
\hline *Ireton-Jones et al (22) & 4540 & $0.66 / 1000$ catheter days & 2005 \\
\hline Lloyd et al (23) & 188 & $.85 / 1000$ catheter days & 2006 \\
\hline Santarpia et al (24) & 222 & $3.20 / 1000$ catheter days & 2002 \\
\hline Ugur et al (25) & 202 & $1.30 / 1000$ catheter days & 2006 \\
\hline Violante et al (26) & 159 & $2.89 / 1000$ catheter days & 2006 \\
\hline Cotogni et al (27) & 254 & $.35 / 1000$ catheter days & 2013 \\
\hline Vashi et al (28) & 241 & $.54 / 1000$ catheter days & 2017 \\
\hline Buchman et al (17) & 135 & $.35 / 1000$ catheter days & 2013 \\
\hline Dibb et al (29) & 588 & $.38 / 1000$ catheter days & 2016 \\
\hline
\end{tabular}

*Report was on catheter-related infections (CRI) which included both CRBSI and CVC exit site infections. 
Figures

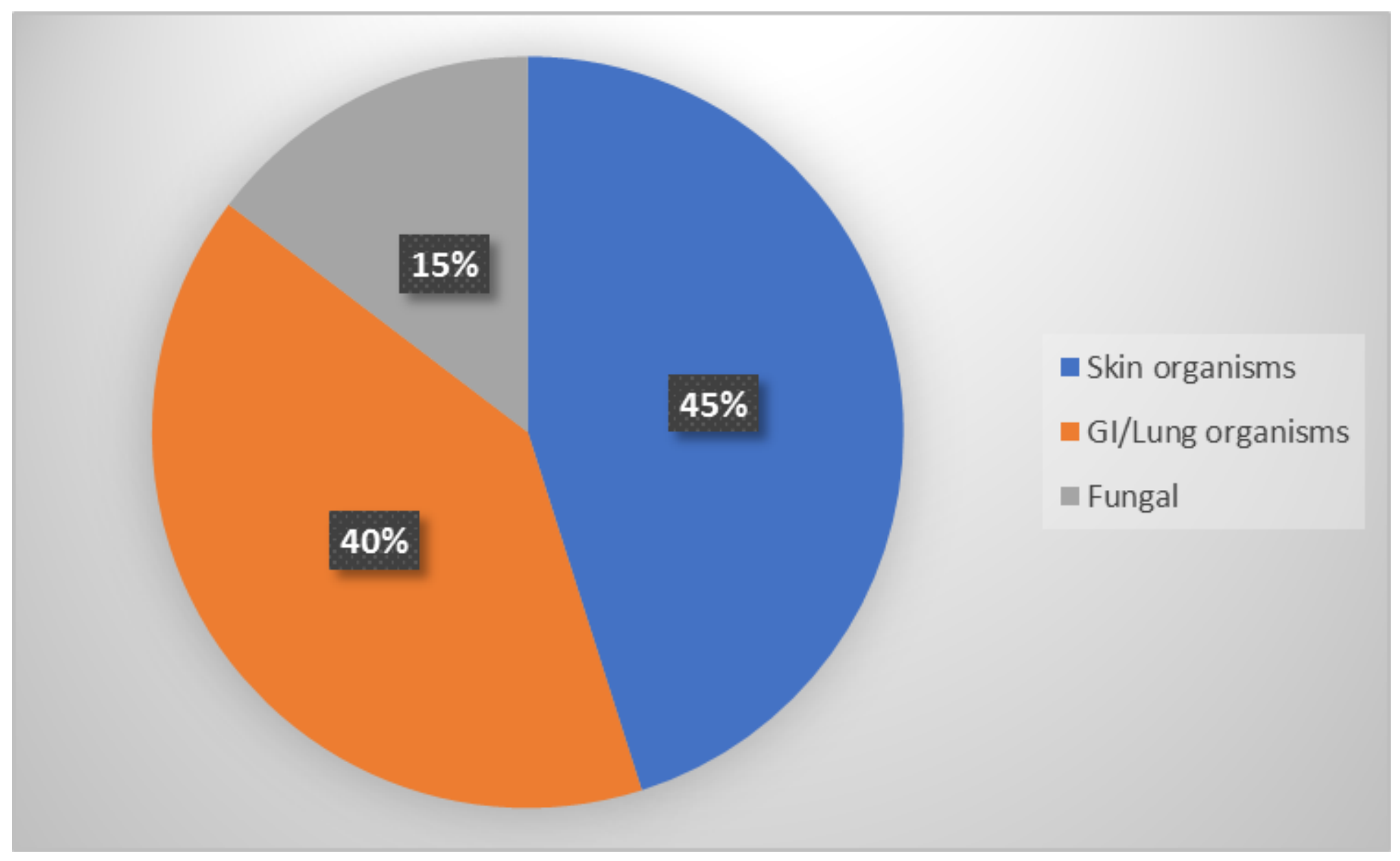

Figure 1

Catheter Related Bloodstream Infection Organism Site of Origin 


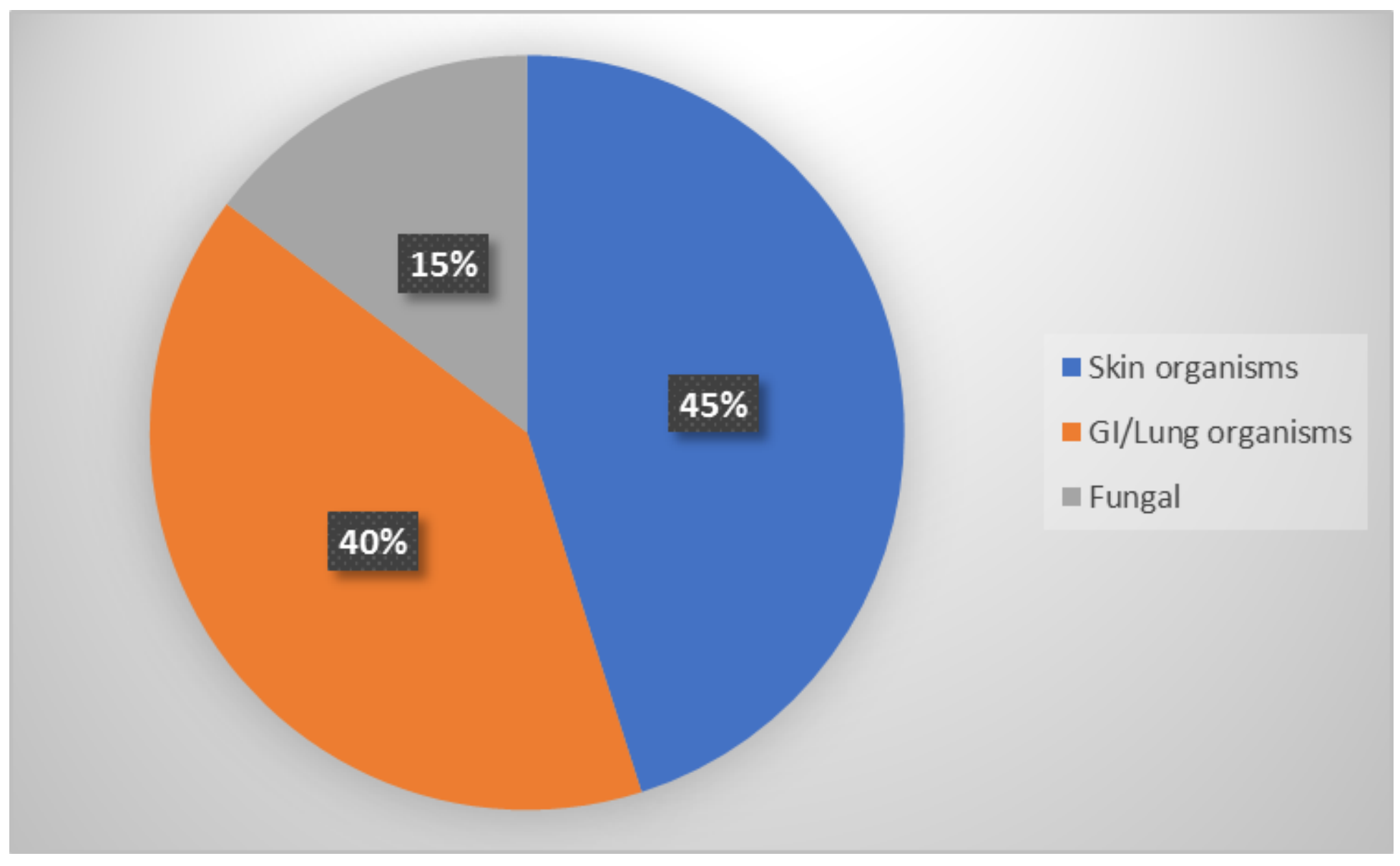

\section{Figure 1}

Catheter Related Bloodstream Infection Organism Site of Origin 